\title{
Salário Mínimo e Desigualdade no Brasil entre 1981-1999: Uma Abordagem Semiparamétrica*
}

\author{
Naercio Menezes-Filho ${ }^{\dagger}$, Eduardo Augusto de Souza Rodrigues ${ }^{\ddagger}$
}

\author{
Contents: 1. Introdução; 2. Metodologia; 3. Dados; 4. Resultados; 5. Considerações Finais; \\ A. Demonstração. \\ Keywords: Salário Mínimo; Educação; Desigualdade Salarial; Kernel. \\ JEL Code: C14; D33; H53; J38.
}

Este trabalho apresenta uma abordagem semiparamétrica para analisar o efeito do salário mínimo na distribuição salarial do Brasil entre 1981 e 1999. A estratégia utilizada baseia-se na desenvolvida por DiNardo et al. (1996) e que ainda não havia sido empregada para o Brasil. Além do salário mínimo, verificamos os efeitos de outros três fatores, a fim de comparar a importância de cada um deles na evolução da desigualdade brasileira. São eles: i) a distribuição do nível educacional; ii) o grau de sindicalização; e iii) outras características individuais. Utilizamos dados das PNADs e um estimador não paramétrico (Kernel) da densidade dos salários com pesos apropriados para captar os efeitos de cada um dos fatores. Uma das principais contribuições desse método é permitir uma representação visual clara do impacto de cada um desses fatores e em quais pontos da distribuição salarial cada um exerce maior influência. Os resultados apontam para efeitos importantes do mínimo sobre a desigualdade brasileira. This work presents a semiparametric procedure to analyze the effect of minimum wage on the Brazilian's distribution of wages over 1981 to 1999. We have followed the approach developed by DiNardo et al. (1996) which has not been implemented to Brazilian's data yet. We investigate further the effects of three other factors, in order to compare their importance on the Brazilian's inequality evolution. The other factors are: i) the distribution of workers' education; ii) the unionization level; and iii) the distribution of workers' attributes other than education and unionization. Using data from PNAD and applying Kernel density methods to appropriately weighted samples, we capture the effects of each one of the four

\footnotetext{
* Os autores agradecem os comentários, sugestões e críticas de Paulo Picchetti, André Portela, Marcelo Neri, Antônio Gledson, Márcio Issao Nakane e Fábio Kanczuk. A visão expressa aqui e os erros cometidos são de inteira responsabilidade dos autores.

${ }^{\dagger}$ Insper - Instituto de Ensino e Pesquisa e Universidade de São Paulo (FEA-USP). E-mail: NaercioAMF@insper .org. br

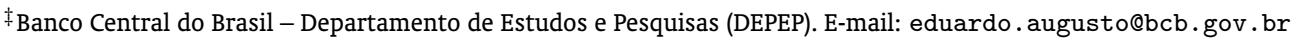


factors considered. This procedure yields a visually clear representation of precisely where in the distribution various factors have their greatest impact. The results show important effects of minimum wage on Brazilian inequality.

\section{INTRODUÇÃO}

As investigações sobre os determinantes da desigualdade no Brasil ganharam força no meio acadêmico a partir do início da década de 70 com a constatação de que a desigualdade de renda havia aumentado durante a década anterior. Uma das principais questões que se colocou desde o início do debate referese ao peso de alguns fatores explicativos na desigualdade de renda existente no Brasil. De um lado, havia uma corrente que defendia que a escolaridade era a principal explicação causal das disparidades das rendas. De outro, a corrente que enfatizava o acesso à propriedade (terra e capital) e o papel de instituições tais como as políticas salariais definidas pelo governo - como a do salário mínimo - e os sindicatos.

Com relação ao papel do salário mínimo na desigualdade, o debate sempre foi bastante controverso, pois, apesar do objetivo da legislação sobre o mínimo ser o de redistribuir os ganhos para os trabalhadores mais mal remunerados para garantir a satisfação de suas necessidades básicas, tal política pode ter efeitos ambíguos, já que existe uma série de trade-off e efeitos indiretos envolvidos.

No Brasil, o debate sobre os efeitos do mínimo sobre a desigualdade ganhou força com a publicação do artigo de Macedo and Garcia (1978), no qual os autores contestaram a importância do salário mínimo na determinação dos salários dos trabalhadores não qualificados. Tal artigo desencadeou uma série de trabalhos que investigavam a importância do mínimo sobre a distribuição de salários. Frequentemente, com base em regressões, os pesquisadores encontravam relações negativas entre o mínimo e a concentração salarial e relações positivas entre o mínimo e o salário real médio (Velloso, 1990, Cacciamali et al., 1994).

Mais recentemente, alguns trabalhos procuraram verificar efeitos diferenciados do mínimo ao longo da distribuição de salários ao invés de fazer regressões contrapondo o salário mínimo com uma medida de concentração salarial ou com o salário médio da economia. Fajnzylber (2001) utilizou dummies para cada faixa de salários em suas regressões a fim de captar esses efeitos diferenciados e apontou impactos sempre significativos de reajustes do mínimo nas demais posições da distribuição dos salários. Ele estimou a variação percentual dos ganhos de um indivíduo como função da variação percentual do salário mínimo e da variação percentual do salário mínimo defasado em um ano, além de alguns controles. As elasticidades obtidas são próximas de um para aqueles com remuneração próxima do mínimo e caem à medida em que os rendimentos ficam maiores. Esses efeitos tendem a ser maiores no curto prazo, para homens, para chefes de famílias e valem tanto para os trabalhadores do setor formal como para os do setor informal.

Lemos (2002a,b) utilizou regressões quantílicas e obteve resultados um pouco parecidos com os de Fajnzylber. A autora mostra efeitos positivos do mínimo sobre os salários de todos os decis, com efeitos maiores nos decis inferiores. Mais especificamente, a autora encontrou elasticidades renda do salário mínimo próximas de 0.5 para indivíduos entre os quantis $10^{\circ}$ e $15^{\circ}$. Essas elasticidades caem até atingir zero para os que estão acima do nono decil. Este resultado é robusto a diversas especificações de medida do mínimo, o que permite à autora concluir que aumentos do mínimo tendem a diminuir a dispersão salarial.

Soares (2001) também procurou estimar esses efeitos seguindo de perto as versões anteriores do trabalho de Lemos, porém, considerando apenas o período pós Plano Real. Ele encontrou elasticidades próximas de 0.2 para os centis inferiores; 0.6 para os centis próximos do mínimo antes do aumento; e zero para os dois quintos superiores da distribuição, e concluiu que o mínimo teria efeitos redistributivos pequenos. 
A investigação dos efeitos diferenciados do salário mínimo sobre a distribuição salarial foi, sem dúvida, um avanço metodológico na discussão sobre a sua importância. $O$ presente trabalho também procura verificar o impacto do mínimo sobre toda a densidade salarial, entretanto, não impõe $a$ priori uma relação funcional entre as variáveis. O tipo de pergunta a que pretendemos responder é: "qual seria a distribuição salarial em 1988 se o salário mínimo fosse o mesmo que o observado em 1981?". Para tal, implementaremos uma abordagem semiparamétrica proposta por DiNardo et al. (1996) que ainda não foi empregada no Brasil.

Consideramos cinco fatores explicativos da distribuição salarial:

(i) variações do salário mínimo real;

(ii) mudança no grau de sindicalização;

(iii) mudanças no nível de escolaridade dos trabalhadores;

(iv) mudanças na distribuição das características individuais, exceto o nível de sindicalização e de escolaridade; $\mathrm{e}$

(v) mudanças residuais. ${ }^{1}$

Utilizamos os dados das PNADs e faremos o mesmo exercício para os períodos de 1981-1988 e de 1988-1999 separadamente, a fim de observar a robustez de cada fator explicativo. Faremos o exercício separadamente também para os setores formais e informais da economia.

Esta abordagem decompõe a diferença entre as distribuições dos períodos considerados pelos fatores enumerados acima. Ela pode, portanto, indicar a importância potencial desses fatores, bem como comparar o peso relativo de cada um deles sobre os salários. Além disso, uma de suas principais contribuições é permitir uma representação visual clara do impacto de cada um deles e em quais pontos da distribuição salarial cada um exerce maior influência.

Este trabalho está dividido em cinco seções, incluindo esta introdução. Na seção 2, apresentamos a metodologia empregada. Na terceira, descrevemos os dados utilizados. Na quarta seção, apresentamos os resultados. E, por fim, tecemos as considerações finais.

\section{METODOLOGIA}

A metodologia desse trabalho, como já dissemos, seguirá a estratégia proposta por DiNardo et al. (1996). Essa abordagem é bastante similar à decomposição de Oaxaca. No entanto, em vez de trabalhar com médias, a decomposição é baseada na distribuição dos salários. Ela é feita com base em distribuições contrafactuais simples tais como "qual seria a densidade dos salários em 1988 se as características dos trabalhadores fossem as mesmas que as observadas em 1981?".

$O$ efeito potencial de cada fator será medido com base nas densidades contrafactuais associadas a cada um deles. Diremos que a diferença entre a densidade de 1988 e a densidade contrafactual associada ao salário mínimo, por exemplo, nos dará o efeito potencial que esse fator teria sobre a distribuição salarial. A diferença entre a densidade contrafactual do mínimo e a contrafactual associada ao nível de sindicalização, por sua vez, nos daria o efeito potencial dos sindicatos já descontados os efeitos do mínimo, e assim por diante até esgotarmos todos os fatores escolhidos. A diferença entre a densidade do último fator considerado e a densidade de 1981 captaria as mudanças não explicadas. E, naturalmente, a soma de todos os efeitos será igual à diferença entre as densidades de 1988 e de 1981. Formalmente, temos que

\footnotetext{
${ }^{1}$ DiNardo et al. (1996) não separaram educação dos demais atributos individuais e consideraram efeitos de demanda e oferta de trabalho como mais um fator explicativo.
} 


$$
\begin{aligned}
f_{88}(w)-f_{81}(w)= & \left\{f_{88}(w)-f_{S M}(w)\right\} \\
& +\left\{f_{S M}(w)-f_{u}(w)\right\} \\
& +\left\{f_{u}(w)-f_{e}(w)\right\} \\
& +\left\{f_{e}(w)-f_{h}(w)\right\} \\
& +\left\{f_{h}(w)-f_{81}(w)\right\}
\end{aligned}
$$

onde $f_{S M}(w)$ é a densidade contrafactual associada ao salário mínimo; $f_{u}(w)$, é a densidade contrafactual associada à sindicalização; $f_{e}(w)$, é a associada à educação; e $f_{h}(w)$, é a associada às demais características individuais.

Ao fazermos essa decomposição, calcularemos quatro medidas de desigualdades para cada distribuição: o desvio-padrão do logaritmo dos salários reais; a razão entre o salário do nono decil e o do primeiro decil; o índice de Gini; e o coeficiente de entropia de Theil (o T de Theil). Em seguida, computaremos a diferença entre as medidas de desigualdade de diferentes distribuições seguindo a ordem da decomposição acima. Por exemplo, dado que o salário mínimo real de 1981 é maior que o de 1988, ao calcularmos a diferença entre o índice de Gini de 1988 e o Gini do contrafactual associado ao salário mínimo, se o valor dessa diferença for positivo, então o efeito de um maior salário mínimo em 1988 seria o de reduzir a dispersão salarial. 0 que nos sugere que a queda no valor do mínimo observada ao longo do período teria servido para ampliar a desigualdade. Se a diferença dos índices for negativa, a conclusão é que, ao contrário, a queda do mínimo teria servido para reduzir a desigualdade nesse intervalo de tempo. Além disso, quando dividimos essa diferença pela diferença total do período - isto é, pela diferença entre os Ginis de 1988 e 1981 - obtemos uma medida da parcela da variação da desigualdade devida ao salário mínimo. Com base nesta medida, podemos comparar o peso relativo de cada fator explicativo na decomposição.

Exporemos também as figuras dos contrafactuais, a fim de visualizar em quais pontos das distribuições os fatores têm maior influência. Neste caso, optamos por expor as figuras do logaritmo dos salários reais, pois as figuras dos salários reais apresentam excessiva super suavização em virtude da presença de outliers que têm ganhos extremamente elevados advindos do trabalho. $\mathrm{O}$ uso do logaritmo compacta a densidade, diminui um pouco o problema da super suavização e permite uma melhor inspeção visual dos efeitos de cada fator.

É importante ressaltar ainda que, como o efeito de cada fator depende da ordem da decomposição, devemos inverter a ordem da decomposição na estimação, a fim de não superestimar o impacto de alguns componentes.

Para estimarmos a densidade dos salários mensais, utilizamos o método de Kernel adaptado para incluir pesos amostrais para cada observação. Para as densidades contrafactuais, utilizamos também o método de Kernel, porém, com a escolha cuidadosa de um reponderador.

\subsection{Distribuição dos salários}

O estimador Kernel de uma função densidade de probabilidade, $f(w)$, é obtida não parametricamente por meio da seguinte fórmula - adaptada para incluir os pesos amostrais para cada observação:

$$
\hat{f}(w)=\sum_{i \in S} \frac{\theta_{i}}{b} \cdot K\left(\frac{w-W_{i}}{b}\right)
$$

onde $\theta_{i}$ é o peso amostral da observação $i$ (que é o peso de cada ponto da amostra da PNAD); $S$ é o conjunto dos índices das observações da amostra; $b$ é o parâmetro de suavização (bandwidth); $K($.) é a função Kernel; e $W_{i}$ são os salários amostrais. 
A função Kernel utilizada será a Gaussiana, e o parâmetro de suavização, $b$, será escolhido com base na sugestão de Silverman (1986):

$$
b=0.9 \cdot N^{-1 / 5} \cdot\left\{\min \left(\hat{\sigma}, \frac{I Q R}{1.349}\right)\right\}
$$

onde $\sigma$ é o desvio padrão amostral de $W$ e $I Q R$ é o intervalo interquartil de $W$ (a diferença entre o $75 \mathrm{~h}$ e o $25 \mathrm{~h}$ percentis).

\subsection{Contrafactuais}

Para as densidades contrafactuais, como já dissemos, será utilizado também o método de Kernel com a escolha cuidadosa de um reponderador. A escolha do reponderador é simples e engenhosa.

Tomemos os dois anos sob análise, 1981 e 1988 (ou 1988 e 1999), e juntemos as observações desses dois anos em um único conjunto. Desse modo, os anos podem ser considerados, dentro desse conjunto, variáveis aleatórias (e podemos associar probabilidades à ocorrência deles). A distribuição dos salários em 1988 pode ser obtida como a distribuição de salários desse conjunto condicionada no ano de 1988. Estendendo um pouco mais esse raciocínio, sabemos que a densidade de salários em um ponto do tempo (em 1988, no caso), $f\left(w ; t_{w}=88\right)$, pode ser obtida como a densidade marginal da densidade conjunta dos salários, $w$, e dos atributos individuais, $z$, onde tanto $w$ como $z$ são aqueles obtidos para $o$ ano de 1988. Formalmente, temos que:

$$
\begin{aligned}
f\left(w ; t_{w}=88\right) & =\int_{z \in \Omega_{z}} f\left(w, z / t_{w}=t_{z}=88\right) d z \\
& =\int_{z \in \Omega_{z}} f\left(w / z, t_{w}=88\right) \cdot d F\left(z / t_{z}=88\right)
\end{aligned}
$$

onde $w$ representa salário, $f(w)$ é a densidade dos salários, $z$ é o conjunto dos atributos individuais, ${ }^{2}$ $\Omega_{z}$ é o conjunto em que estão definidas as características individuais; $t_{w}=88$ indica que os salários são aqueles do ano de 1988; e $t_{z}=88$ indica que as características individuais são aquelas que observamos em 1988.

Se quisermos obter a densidade de salários contrafactual que prevaleceria em 1988 caso a distribuição das características fosse a mesma de 1981, as datas referentes a $t_{w}$ e a $t_{z}$ deverão ser agora, as de 1988 e 1981, respectivamente. Isto é, os salários seriam aqueles de 1988, mas as características seriam as de 1981 .

Admitindo a hipótese que a estrutura de salários em 1988 não dependa da distribuição dos atributos, isto é, que a distribuição dos salários condicionada nas características não dependa da distribuição dessas características, então a densidade contrafactual pode ser obtida de maneira bastante simples:

$$
\begin{aligned}
f_{z}(w) & =\int_{z \in \Omega_{z}} f\left(w / z, t_{w}=88\right) d F\left(z / t_{z}=81\right) \\
& =\int f\left(w / z, t_{w}=88\right) \phi_{z}(z) d F\left(z / t_{z}=88\right)
\end{aligned}
$$

onde $f_{z}(w)$ é a densidade contrafactual associada às características individuas $z$; e o reponderador $\phi_{z}$ é definido como

$$
\phi_{z}(z) \equiv \frac{d F\left(z / t_{z}=81\right)}{d F\left(z / t_{z}=88\right)}
$$

\footnotetext{
${ }^{2}$ As características individuais consideradas são: idade, anos de educação, sexo, região metropolitana, cor, estado em que o indivíduo mora, dummy para carteira de trabalho assinada, dummy para filiação sindical e dummy para jornada de trabalho maior que trinta horas por semana.
} 
É possível demonstrar que o reponderador pode ser reescrito como (ver anexo):

$$
\phi_{z}(z)=\frac{\operatorname{Pr}\left(t_{z}=81 / z\right)}{\operatorname{Pr}\left(t_{z}=88 / z\right)} \cdot \frac{\operatorname{Pr}\left(t_{z}=88\right)}{\operatorname{Pr}\left(t_{z}=81\right)}
$$

Podemos estimar as probabilidades não condicionadas acima utilizando a razão entre o número de observações em um ano e o número de observações do dois anos, ambos os anos ponderados pelos respectivos pesos amostrais das observações. Para estimar as probabilidades condicionadas utilizamos um probit com os seguintes argumentos: anos de educação, sexo, estado, área metropolitana, idade, idade ao quadrado, cor, carteira de trabalho assinada, dummy para filiação sindical e uma dummy para jornada de trabalho maior que trinta horas por semana.

Uma vez que uma estimativa do reponderador for obtida, ela pode ser utilizada para estimar a densidade contrafactual pelo método de Kernel ponderado pelos pesos amostrais.

$$
\hat{f}_{z}\left(w ; t_{w}=88, t_{z}=81\right)=\sum_{i \in S_{88}} \frac{\theta_{i}}{b} \cdot \hat{\phi}_{z}\left(z_{i}\right) \cdot K\left(\frac{w-W_{i}}{b}\right)
$$

onde $S_{88}$ é o conjunto dos índices das observações de 1988. Notemos que se o reponderador for igual a 1, estimaremos a verdadeira densidade salarial de 1988.

É importante assinalar, neste ponto, que a densidade contrafactual, calculada sob a hipótese de que a estrutura de salários em 1988 não depende da distribuição dos atributos, deve ser interpretada, na verdade, da seguinte forma: "qual seria a densidade dos salários em 1988 se as características dos trabalhadores fossem as mesmas que as observadas em 1981 e se os trabalhadores tivessem sido pagos de acordo com o esquema de pagamentos vigente em 1988?". Neste ponto fica claro que, com esta hipótese crucial, efeitos possíveis advindos de um arcabouço de equilíbrio geral são desconsiderados nesta abordagem.

É interessante fazer aqui uma comparação desse contrafactual com os contrafactuais obtidos por meio de regressões. Quando fazemos uma regressão à la Mincer, por exemplo, e queremos observar qual seria o salário de um indivíduo em 1988 se ele apresentasse as características médias de um indivíduo em 1981, colocamos esses valores médios nas covariadas da regressão e, dadas as estimativas obtidas anteriormente pela regressão minceriana, obtemos qual seria o salário contrafactual desse indivíduo. No exercício proposto por este trabalho, porém, os salários contrafactuais não são obtidos para cada indivíduo separadamente, mas para a amostra inteira ao mesmo tempo. Isto é, mudamos as características de todos os indivíduos da amostra e vemos como ficariam seus salários - desconsiderando mudanças no esquema de pagamentos. Isto significa que, neste sentido, este exercício exige uma hipótese muito mais forte que a exigida no caso anterior, qual seja, a de que mudamos as características de todos os agentes sem alterar mais nada na economia, enquanto o tipo de exercício anterior permitia a mudança das características de apenas um indivíduo sem afetar o resto da economia.

Embora tenhamos apresentado o contrafactual dos atributos individuais, para cada fator explicativo teremos um reponderador diferente. Mesmo o reponderador acima deverá ser substituído para que possamos observar o impacto da educação e dos sindicatos separadamente dos demais atributos individuais. Esses reponderadores são obtidos aplicando-se o mesmo raciocínio acima.

Assim, para obter a densidade contrafactual associada aos sindicatos, procedemos da seguinte forma: separamos as características individuais, $z$, em uma dummy associada à sindicalização, $u$, e um vetor das outras características individuais (incluindo educação), $x$. Podemos, daí, reescrever a densidade salarial de 1988 como

$$
\begin{aligned}
& f\left(w ; t_{w}=88, t_{u / x}=88 ; t_{x}=88\right)=\iint f\left(w / u, x, t_{w}=88\right) \cdot d F\left(u / x, t_{u / x}=88\right) \\
& . d F\left(x / t_{x}=88\right)
\end{aligned}
$$


Novamente, sob a hipótese de que a estrutura de salários não depende da taxa de sindicalização, a densidade contrafactual para o caso em que somente o nível de sindicalização permaneça no mesmo nível de 1981 é dada por

$$
\begin{aligned}
f_{u}\left(w ; t_{w}=88, t_{u / x}=81 ; t_{x}=88\right)= & \iint f\left(w / u, x, t_{w}=88\right) \cdot d F\left(u / x, t_{u / x}=81\right) \\
& . d F\left(x / t_{x}=88\right) \\
\equiv & \iint f\left(w / u, x, t_{w}=88\right) \cdot \phi_{u / x}(u, x) \cdot d F\left(u / x, t_{u / x}=88\right) \\
& . d F\left(x / t_{x}=88\right)
\end{aligned}
$$

onde o reponderador é:

$$
\phi_{u / x}(u, x) \equiv \frac{d F\left(u / x, t_{u / x}=81\right)}{d F\left(u / x, t_{u / x z}=88\right)}=\frac{\operatorname{Pr}\left(t_{u / x}=81 / u, x\right)}{\operatorname{Pr}\left(t_{u / x}=88 / u, x\right)} \cdot \frac{\operatorname{Pr}\left(t_{u / x}=88 / x\right)}{\operatorname{Pr}\left(t_{u / x}=81 / x\right)}
$$

Novamente podemos estimar esse reponderador utilizando probit's. No primeiro probit, o polinômio utilizado é o mesmo que o exposto anteriormente, no segundo probit, porém, o polinômio é igual ao anterior exceto por excluir a variável $u$. Se essa exclusão de $u$ afetar muito pouco os valores previstos pelo probit, então o reponderador terá um valor muito próximo de 1 , o que significa que este fator altera muito pouco a distribuição original. Por outro lado, quanto maior a mudança que esta variável impuser sobre os valores previstos da estimação, maior será seu efeito sobre a densidade estimada. Evidentemente que se as variáveis $u$ e $x$ apresentarem alto grau de multicolinearidade, então a exclusão de $u$ na estimação do probit deverá alterar os coeficientes estimados das variáveis $x$. Isto significa que a exclusão de $u$ na estimação capta não apenas os efeitos "líquidos" da sindicalização, mas também os efeitos que surgem em virtude da relação dos sindicatos com as demais variáveis.

Devemos destacar ainda que, como a hipótese crucial nos diz que o esquema de pagamentos deve ser o mesmo que o de 1988, captaremos os efeitos da mudança na composição da amostra filiada a sindicatos, mas não captaremos o efeito das mudanças do prêmio salarial dos trabalhadores sindicalizados. ${ }^{3}$

Finalmente, ressaltamos que, como não há na PNAD de 1981 perguntas sobre sindicalização nem sobre cor, as estimações para se obter os efeitos da sindicalização (e incluindo cor entre os demais atributos individuais) somente serão feitas para o período de 1988-1999. A opção por expor nesta subseção o ano de 1981 teve por objetivo apenas manter a notação uniforme.

Os efeitos potenciais da educação e das demais características individuais são obtidos exatamente da mesma forma. Ressaltamos novamente que, nessa ordem de decomposição, captamos os efeitos da educação e da sua relação com os demais atributos individuais sobre os salários. Além do que separamos o "efeito composição" da educação - calculada aqui - do "efeito preço", uma vez que levamos em conta apenas o nível de escolaridade dos indivíduos. Quanto às demais características individuais, captamos seus efeitos "líquidos", isto é, "limpos" dos efeitos da educação e dos sindicatos.

\subsubsection{Salário mínimo}

Com relação aos efeitos do salário mínimo real o tratamento é um pouco diferente. Até aqui tínhamos alterado apenas as características físicas dos indivíduos, $z$, sem mexer nos preços associados a cada característica. Em outras palavras, mudamos somente a medida. Quando alteramos o salário mínimo, no entanto, mudamos um dos preços da economia. Consequentemente, para podermos avaliar seu efeito, devemos estabelecer hipóteses diretamente sobre a distribuição de salários condicionada

\footnotetext{
${ }^{3}$ Arbache (2002) mostra que esse prêmio salarial é significativo e caiu entre 1988 e 1999.
} 
nas características. DiNardo et al. (1996) consideram três hipóteses para avaliar os efeitos do salário mínimo.

A primeira delas assume que o salário mínimo não tem efeitos sobre os salários que estão acima do maior dos salários mínimos dos dois anos considerados, dada as características individuais, isto é, não se assume diretamente um efeito spillover na distribuição. ${ }^{4}$ A literatura empírica no Brasil indica que o aumento do mínimo tende, na verdade, a afetar toda a distribuição, mas com maiores efeitos concentrados na cauda inferior (Lemos (2002a,b); Fajnzylber (2001); e Soares (2001)). Esta hipótese, portanto, é bastante conservadora pois reduz a magnitude de possíveis efeitos equalizadores do salário mínimo.

A segunda hipótese refere-se à distribuição condicionada abaixo do mínimo. Como os salários dessa parte da densidade são resultados de não cobertura ou de não cumprimento da lei, então essa hipótese assume que, se o salário mínimo em 1988 permanecesse igual ao vigente em 1981, a distribuição dos salários em 1988 abaixo do mínimo de 1981 seria similar à distribuição de 1981 depois de ajustar pelas diferenças na composição da força de trabalho.

Temos então que a densidade contrafactual associada ao salário mínimo é composta por uma parte acima do salário mínimo de 1981 que segue a distribuição de 1988; e uma parte abaixo desse mínimo que segue a distribuição de 1981, ponderada por um fator que permita que a integração dessas partes seja igual a um.

A terceira e última hipótese assume que o mínimo não tem efeitos sobre o desemprego. Essa hipótese está de acordo com os resultados obtidos para o Brasil de que aumentos do mínimo têm elasticidade desemprego muito pequena ou estatisticamente igual a zero (Lemos (2002a,b); Fajnzylber (2001)). Além disso, estes resultados estão de acordo com a literatura internacional, onde é crescente o consenso de que o salário mínimo tem pequenos efeitos sobre o desemprego (Brown, 1999).

Sob essas hipóteses, a densidade salarial de 1988 condicionada nas características individuais e no salário mínimo de 1981 pode ser escrita como

$$
\begin{aligned}
f\left(w / z, t_{w}=88 ; m_{81}\right)= & I\left(w \leq m_{81}\right) \cdot \phi_{w}\left(z, m_{81}\right) \cdot f\left(w / z, t_{w}=81 ; m_{81}\right) \\
& +\left[1-I\left(w \leq m_{81}\right)\right] . f\left(w / z, t_{w}=88 ; m_{88}\right)
\end{aligned}
$$

onde $I\left(\right.$.) é função indicadora e $\phi_{w}$ é o ponderador que torna a integral dessa densidade igual a 1 , e é dado por:

$$
\phi_{w}\left(z, m_{81}\right)=\frac{\operatorname{Pr}\left(w \leq m_{81} / z, t_{w}=88\right)}{\operatorname{Pr}\left(w \leq m_{81} / z, t_{w}=81\right)}
$$

Ao integrarmos a densidade condicional associada ao mínimo, obtemos a densidade contrafactual que prevaleceria em 1988 se o salário mínimo fosse o mesmo de 1981:

$$
f_{S M}\left(w ; t_{w}=88, t_{z}=88, m_{81}\right)=\int f\left(w / z, t_{w}=88 ; m_{81}\right) \cdot d F\left(z / t_{z}=88\right)
$$

Donde:

$$
\begin{aligned}
f_{S M}= & \int I\left(w \leq m_{81}\right) \cdot \phi_{w}\left(z, m_{81}\right) \cdot f\left(w / z, t_{w}=81, m_{81}\right) \cdot d F\left(z / t_{z}=88\right) \\
& +\int\left[1-I\left(w \leq m_{81}\right)\right] \cdot f\left(w / z, t_{w}=88, m_{88}\right) \cdot d F\left(z / t_{z}=88\right)
\end{aligned}
$$

\footnotetext{
${ }^{4}$ Como o salário mínimo de 1981 é maior que o de 1988, então a hipótese resulta que acima do mínimo de 1981, a distribuição contrafactual condicionada em $z$ segue a de 1988. Para o período 1988-1999, temos, da mesma forma, que o mínimo de 1988 é maior que o de 1999.
} 
Logo,

$$
\begin{aligned}
= & \int I\left(w \leq m_{81}\right) \cdot \phi_{w}\left(z, m_{81}\right) \cdot f\left(w / z, t_{w}=81, m_{81}\right) \cdot \phi_{z}(z)^{-1} \cdot d F\left(z / t_{z}=81\right) \\
& +\int\left[1-I\left(w \leq m_{81}\right)\right] \cdot f\left(w / z, t_{w}=88, m_{88}\right) \cdot d F\left(z / t_{z}=88\right)
\end{aligned}
$$

O reponderador associado ao salário mínimo, para os valores abaixo do mínimo de 1981, portanto, pode ser definido como

$$
\phi_{m}\left(z, m_{81}\right) \equiv \phi_{w}\left(z, m_{81}\right) \cdot \phi_{z}(z)^{-1}
$$

Acima desse mínimo, ele é igual a 1. Como nos casos anteriores, podemos obter

$$
\phi_{m}\left(z, m_{81}\right)=\frac{\operatorname{Pr}\left(t_{w}=88 / z, w \leq m_{81}\right)}{\operatorname{Pr}\left(t_{w}=81 / z, w \leq m_{81}\right)} \cdot \frac{\operatorname{Pr}\left(t_{z}=81\right)}{\operatorname{Pr}\left(t_{z}=88\right)}
$$

Concluímos aqui que o efeito do mínimo sobre a distribuição dependerá fundamentalmente do comportamento da parte da amostra que recebe menos que o salário mínimo real de 1981.

A densidade contrafactual associada ao mínimo parte da densidade de 1988 e altera os atributos individuais $z$ e os prêmios pagos por esses atributos para quem está abaixo do mínimo de 1981. Se essa parcela da população não tiver "evoluído" ao longo do tempo, então o efeito do mínimo será próximo de zero. Se, ao contrário, as características deles mudarem bastante ao longo do período, bem como os prêmios pagos por elas, então o mínimo terá grandes efeitos sobre a distribuição.

Vale destacar ainda que, ao estimarmos essa densidade contrafactual, a parte dela que estiver acima do novo mínimo não deverá ser igual à densidade original de 1988, pois a estimação num ponto por Kernel utiliza informações de toda a amostra e, no caso desse contrafactual, a amostra utilizada é diferente da usada para obter a densidade de 1988.

\section{DADOS}

Os dados utilizados para medir os impactos potenciais de cada fator explicativo são os das PNADs (Pesquisa Nacional por Amostra de Domicílios) de 1981, 1988 e 1999. A amostra é composta por indivíduos que têm entre 18 e 65 anos e que têm alguma remuneração positiva vinda da principal fonte de trabalho do mês de referência. ${ }^{5}$ O salário nominal foi deflacionado pelo Índice Nacional de Preços ao Consumidor (INPC), a preços de janeiro de 2002, e levamos em consideração as mudanças monetárias ocorridas a partir de 1986 (Corseuil and Foguel, 2002). Tendo em vista que o salário mínimo não era unificado até o ano de 1984, utilizamos apenas os dados referentes às regiões Sul, Sudeste e ao Distrito Federal, que tinham salários mínimos iguais entre si mesmo antes de $1984 .^{6}$

Seguindo a Tabela 1, vemos que o salário mínimo real caiu ao longo do período. A proporção de homens na amostra também caiu, cerca de sete pontos percentuais. O nível médio de educação elevouse em quase 1,7 anos entre 1981 e 1999. A idade média aumentou pouco mais de 2 anos. A proporção de trabalhadores com carteira assinada diminuiu sensivelmente ao longo de todo período. A parcela dos indivíduos que trabalharam acima de trinta horas na semana de referência (os trabalhadores fulltime) e a de residentes em áreas metropolitanas apresentaram uma queda acentuada. A porcentagem de brancos manteve-se bastante estável no período (de 1988 a 1999), assim como a de pardos e de negros, embora não esteja exposto na tabela. E, finalmente, o nível de sindicalização subiu de 14,5\% para 17,6\% (também entre 1988 e 1999).

\footnotetext{
${ }^{5}$ Fizemos também este mesmo exercício com os salários horários, em vez de utilizarmos os salários mensais. Os resultados qualitativos foram os mesmos, exceto pela supersuavização das figuras obtida no caso dos salários horários.

${ }^{6}$ Apresentamos as estimações para todo o país no período de 1988 a 1999 em versões anteriores desse artigo. Ver Rodrigues and Menezes-Filho $(2003,2004)$.
} 
Table 1: Estatísticas descritivas

\begin{tabular}{|l|c|c|c|}
\hline & 1981 & 1988 & 1999 \\
\hline Salário mínimo real* & 230,44 & 175,9 & 160,77 \\
Proporção de homens & $68,14 \%$ & $64,69 \%$ & $61,56 \%$ \\
Educação & 5,37 & 5,92 & 7,07 \\
Idade & 34,27 & 34,6 & 36,8 \\
Cart. assinada & $66,69 \%$ & $63,90 \%$ & $58,69 \%$ \\
Full-time status & $91,27 \%$ & $89,94 \%$ & $88,02 \%$ \\
Área metrop. & $50,41 \%$ & $44,09 \%$ & $42,82 \%$ \\
Cor (brancos) & $\mathrm{xx}$ & $52,68 \%$ & $53,25 \%$ \\
Sindicalizados & $\mathrm{xx}$ & $14,56 \%$ & $17,62 \%$ \\
\hline
\end{tabular}

: Fonte: PNAD. *Salário mínimo deflacionado pelo INPC e corrigido para as mudanças monetárias do período.

\section{RESULTADOS}

\subsection{Período de 1981-1988}

\subsubsection{Estatísticas}

Sabemos que, no período de 1981-1988, a desigualdade salarial aumentou. A Tabela 2 mostra as diferenças entre os índices de desigualdade das distribuições estimadas. De fato, vemos na segunda coluna (a coluna de Mudança total) que a diferença entre as medidas de desigualdade de 1988 e de 1981 é positiva para todos os índices, isto é, os índices de desigualdade de 1988 são sempre maiores que os de 1981.

Com relação aos efeitos do salário mínimo, notamos na terceira coluna que, para todos os índices de desigualdade, as diferenças entre as medidas de 1988 e as medidas do contrafactual associado ao salário mínimo são também sempre positivas. Isto significa que, se em 1988 o salário mínimo real fosse igual ao de 1981, isto é, se ele tivesse sido maior que o observado em 1988, a desigualdade salarial teria sido menor do que a que prevaleceu em 1988. Isto sugere que ao longo do período, a queda do mínimo em termos reais teria servido para aumentar a dispersão salarial. Seu efeito explica, para os homens, $73 \%$ da variação do Gini e $66 \%$ da variação do Theil; e, para as mulheres, $123 \%$ da variação do Gini e $107 \%$ da variação do Theil.

Quando revertemos a ordem da decomposição (exposta na parte de baixo da Tabela 2), notamos, em primeiro lugar, que a importância do mínimo cai. Entre os homens ele passa a explicar $17 \%$ da variação do Gini e somente $6,5 \%$ da variação do Theil. Entre as mulheres, $40 \%$ da variação do Gini e $25 \%$ da variação do Theil. Notamos ainda que o salário mínimo, para qualquer ordem de decomposição utilizada, explica pelo menos $65 \%$ da variação da razão entre os salários do nono decil e do primeiro decil tanto para homens como para mulheres.

Com relação à educação, lembrando aqui que se trata apenas do efeito composição, seus efeitos foram o de aumentar a desigualdade no período. Na Tabela 2, na quarta coluna, vemos que se a escolaridade em 1988 fosse a mesma de 1981, isto é, com média menor e menos dispersa, a desigualdade seria menor, para qualquer índice utilizado. Esse resultado está plenamente de acordo com a curva de Kusnetz, em que um aumento da média educacional acompanhada de um aumento na sua dispersão leva a uma maior desigualdade de ganhos. Esse fator explica $56 \%$ da variação do Gini e $42 \%$ da variação 
Table 2: Diferenças entre os índices de desigualdade

\begin{tabular}{|c|c|c|c|c|c|c|}
\hline \multicolumn{7}{|c|}{ Decompondo as mudanças dos índices de dispersão salarial:1981-1988 } \\
\hline \multirow[b]{2}{*}{ Estatística } & \multirow[b]{2}{*}{$\begin{array}{l}\text { Mudança } \\
\text { total } \\
\text { 1988-1981 }\end{array}$} & \multicolumn{5}{|c|}{ Efeitos de: } \\
\hline & & \multicolumn{2}{|c|}{ Salário mínimo } & Educação & $\begin{array}{l}\text { Características } \\
\text { individuais }\end{array}$ & $\begin{array}{c}\text { Mudanças não } \\
\text { explicadas }\end{array}$ \\
\hline \multicolumn{7}{|l|}{ Homens } \\
\hline \multirow[t]{2}{*}{ Desvio-Padrão } & \multirow[t]{2}{*}{0,103} & \multicolumn{2}{|c|}{0,117} & 0,052 & 0,004 & $-0,071$ \\
\hline & & \multicolumn{2}{|c|}{$113,82 \%$} & $50,28 \%$ & $4,53 \%$ & $-68,63 \%$ \\
\hline \multirow[t]{2}{*}{$90-10$} & 1,978 & 1,348 & $68,16 \%$ & 1,966 & 0,000 & $-1,336$ \\
\hline & & & & $99,41 \%$ & $0,00 \%$ & $-67,57 \%$ \\
\hline \multirow[t]{2}{*}{ Gini } & 0,048 & 0,035 & $73,55 \%$ & 0,027 & 0,001 & $-0,015$ \\
\hline & & & & $55,94 \%$ & $3,03 \%$ & $-32,53 \%$ \\
\hline \multirow[t]{2}{*}{ Theil } & 0,113 & 0,074 & $65,97 \%$ & 0,048 & 0,001 & $-0,011$ \\
\hline & & & & $42,53 \%$ & $1,65 \%$ & $-10,17 \%$ \\
\hline \multicolumn{7}{|l|}{ Mulheres } \\
\hline \multirow[t]{2}{*}{ Desvio-Padrão } & 0,085 & & 01 & 0,025 & 0,009 & $-0,151$ \\
\hline & & & $09 \%$ & $29,46 \%$ & $11,57 \%$ & $-178,13 \%$ \\
\hline \multirow[t]{2}{*}{$90-10$} & 2,321 & & 61 & 0,485 & 0,000 & $-4,626$ \\
\hline & & & $35 \%$ & $20,93 \%$ & $0,00 \%$ & $-199,28 \%$ \\
\hline \multirow[t]{2}{*}{ Gini } & 0,052 & & 65 & 0,017 & 0,003 & $-0,032$ \\
\hline & & & $52 \%$ & $32,72 \%$ & $5,84 \%$ & $-62,07 \%$ \\
\hline \multirow[t]{2}{*}{ Theil } & 0,124 & & 33 & 0,026 & 0,005 & $-0,041$ \\
\hline & & & $61 \%$ & $21,15 \%$ & $4,33 \%$ & $-33,09 \%$ \\
\hline \multicolumn{7}{|c|}{ Revertendo a ordem de decomposição: 1981-1988 } \\
\hline & $\begin{array}{c}\text { Mudança } \\
\text { total }\end{array}$ & \multicolumn{2}{|c|}{$\begin{array}{c}\text { Características } \\
\text { individuais }\end{array}$} & Educação & $\begin{array}{c}\text { Salário } \\
\text { mínimo }\end{array}$ & $\begin{array}{c}\text { Mudanças não } \\
\text { explicadas }\end{array}$ \\
\hline \multicolumn{7}{|l|}{ Homens } \\
\hline \multirow[t]{2}{*}{ Desvio-padrão } & 0,103 & & 03 & 0,025 & 0,046 & $-0,071$ \\
\hline & & & $77 \%$ & $24,21 \%$ & $44,94 \%$ & $-68,63 \%$ \\
\hline \multirow[t]{2}{*}{$90-10$} & 1,978 & & 48 & 0,973 & 1,293 & $-1,336$ \\
\hline & & & $0 \%$ & $49,21 \%$ & $65,36 \%$ & $-67,57 \%$ \\
\hline \multirow[t]{2}{*}{ Gini } & 0,048 & & 42 & 0,013 & 0,008 & $-0,015$ \\
\hline & & & $38 \%$ & $26,86 \%$ & $17,77 \%$ & $-32,53 \%$ \\
\hline \multirow[t]{2}{*}{ Theil } & 0,113 & & 95 & 0,022 & 0,007 & $-0,011$ \\
\hline & & & $8 \%$ & $19,59 \%$ & $6,50 \%$ & $-10,17 \%$ \\
\hline Mulheres & & & & & & \\
\hline Desvio-padrão & 0,085 & & 49 & 0,013 & 0,073 & $-0,151$ \\
\hline & & & $02 \%$ & $16,29 \%$ & $86,82 \%$ & $-178,13 \%$ \\
\hline $90-10$ & 2,321 & & 97 & 1,019 & 1,530 & $-4,626$ \\
\hline & & & $42 \%$ & $43,91 \%$ & $65,95 \%$ & $-199,28 \%$ \\
\hline Gini & 0,052 & & 57 & 0,007 & 0,021 & $-0,032$ \\
\hline & & & $80 \%$ & $13,37 \%$ & $39,89 \%$ & $-62,07 \%$ \\
\hline Theil & 0,124 & & 25 & 0,008 & 0,031 & $-0,041$ \\
\hline & & & $19 \%$ & $6,98 \%$ & $24,92 \%$ & $-33,09 \%$ \\
\hline
\end{tabular}

: Fonte: Tabela construída pelos autores com base nos dados das PNDAs. 
do Theil entre os homens; $33 \%$ do Gini e $21 \%$ do Theil entre as mulheres. É interessante notar aqui que o peso relativo do salário mínimo é maior que o da composição educacional.

$\mathrm{Na}$ ordem inversa, a parcela explicada pela educação também cai, mas devemos lembrar aqui que, nesse caso, o efeito da educação está limpo dos efeitos das demais características individuais. Chamamos a atenção para o fato de que para alguns índices, o efeito do mínimo ainda é maior que o da educação.

As demais características individuais têm efeitos sempre próximos de zero - quando não exatamente iguais a zero, como no caso da razão 90/10. Mas, curiosamente, seus efeitos ficam extraordinariamente grandes quando invertermos a ordem. Concluímos que as características individuais têm pouca importância sobre a distribuição quando consideradas isoladamente, mas seus efeitos são grandes quando relacionados com a educação. De qualquer modo, a distribuição contrafactual desses atributos teve sempre dispersão menor que as distribuições com as quais se contrapôs, o que indica que a evolução dessas características - como a queda na proporção de homens, o aumento da idade média, a queda na proporção de trabalhadores no setor formal da economia, a diminuição de trabalhadores em áreas metropolitanas - também serviu para aumentar a desigualdade no período.

Finalmente, as mudanças residuais devem ser interpretadas da seguinte forma: se tudo o mais, exceto os fatores já destacados, tivessem sido em 1988 iguais aos de 1981, como ficaria a distribuição salarial? Vemos que, neste caso, a desigualdade teria sido maior, pois na última coluna da Tabela 1 todos os índices indicam aumento de dispersão. Isto significa que o efeito líquido das demais mudanças ao longo do período serviu para diminuir a desigualdade. Isso, piorem, não implica que alguns fatores isolados, como variações tecnológicas ou efeitos macro, por exemplo, tenham atuado no sentido de diminuir a má distribuição no período.

\subsubsection{Figuras}

Quando nos voltamos às figuras das distribuições, vemos em primeiro lugar, nas figuras de mudanças totais (Figuras 1a e 1b), que as distribuições de 1981 são mais compactas que as de 1988, como já era de se esperar. No entanto, há dois pontos interessantes a notar aqui: primeiro, as distribuições apresentam um pico em torno dos respectivos salários mínimos - embora para os homens seja um pouco mais sutil, o que pode sugerir que ou o salário mínimo é uma restrição mais efetiva para elas que para eles, ou podemos ter apenas um problema de supersuavização na estimação para os homens. Como destacam Amadeo et al. (2000), a concentração de massa no valor do mínimo sugere que a legislação atua como binding na distribuição salarial, pois, na ausência do mínimo, todos os pontos da distribuição deveriam ter massa zero. Além disso, esses autores, encontram, para 1998, uma proporção em torno de $10 \%$ dos salários com valor igual ao do mínimo.?

O segundo ponto a que chamamos atenção é que a densidade das mulheres é mais concentrada em torno do mínimo que a dos homens. Essas duas observações sugerem por que o mínimo apresentou impactos maiores sobre as mulheres do que sobre os homens conforme exposto na subseção anterior.

Olhando agora para as Figuras (1c) e (1d), percebemos que o efeito do aumento do mínimo, tanto para homens como para mulheres, é o de achatar a cauda inferior e aumentar a densidade dos salários acima do mínimo, empurrando a distribuição para a direita. De fato, esse deslocamento é maior entre as mulheres. O salário mínimo teve ainda o efeito sugerido por Lemos (2002a): empurrou a distribuição para a direita (o que aumentou a média) e diminuiu o logaritmo da variância. Além disso, podemos ver que os maiores efeitos estão logo acima do mínimo e caem à medida que os salários aumentam, o que está de acordo com o que vem sendo encontrado na literatura brasileira (Lemos (2002a,b); Fajnzylber (2001); e Soares (2001)). Este efeito pode ser interpretado como resultado de mudanças na composição da força de trabalho utilizada pelas firmas, ou seja, o aumento dos salários dos trabalhadores diretamente afetados (isto é, aqueles que recebem entre o novo e o velho o mínimo) torna mais atrativa a

\footnotetext{
${ }^{7}$ Destacamos ainda, de acordo com esses autores, o fato de que alguns múltiplos do salário mínimo também apresentam massa diferente de zero. A metodologia adotada neste trabalho, porém, não consegue captar todas essas concentrações em virtude da suavização empregada. Agradecemos a Marcelo Neri por nos chamar a atenção para esse ponto.
} 
substituição deles por outros um pouco mais qualificados (que recebem um pouco acima do novo mínimo) e o aumento de demanda por estes últimos deverá aumentar seus ganhos. Além disso, como os efeitos estimados propagam-se por quase toda a distribuição, esse resultado também é consistente com o chamado "efeito farol" - que pode resultar da barganha dos trabalhadores para manter seus ganhos relativos após um aumento do mínimo.

Quanto à educação, notamos que, para homens e mulheres, o efeito é o de engordar um pouco a cauda inferior, aumentar um pouco a concentração em torno da moda e achatar um pouco a cauda superior, como se a densidade fosse empurrada para a esquerda (diminuindo a média) e tivesse sua dispersão diminuída. Esse resultado está de acordo com os resultados encontrados por Menezes-Filho et al. (2000), no qual a distribuição educacional teria servido para aumentar a desigualdade nas últimas décadas (e só contribuiria com a redução da dispersão a partir dos próximos 10 anos). Por fim, a densidade contrafactual dos atributos individuais difere muito pouco da densidade anterior. ${ }^{8}$

\subsection{Período de 1988-1999}

\subsubsection{Estatísticas}

Fizemos o mesmo exercício para o período de 1988-1999. Nesta fase, a desigualdade diminuiu. Na Tabela 3, observamos que os resultados da decomposição foram qualitativamente os mesmos do período anterior, embora as magnitudes dos efeitos tenham variado um pouco. Chamamos a atenção apenas para alguns pontos: a variação real do salário mínimo neste período foi menor que a variação do período anterior, o que sugere por que seus efeitos na primeira ordem de decomposição tenham sido menores agora. Além disso, notamos que as mudanças residuais são a maior fonte de variação dos índices, o que significa que pouco podemos explicar para este período com essa abordagem. Podemos ver, no entanto, que elas novamente atuaram no sentido de diminuir a desigualdade ao longo do período.

\subsubsection{Figuras}

Observando as figuras, percebemos que a densidade salarial das mulheres tornou-se menos concentrada em torno do mínimo em 1999 quando comparada a 1981 e a 1988 e seu padrão fica mais parecido com a densidade dos homens. O pico em torno do mínimo, porém, é maior entre elas do que entre eles. Aqui, novamente, o efeito de um maior salário mínimo seria tornar a densidade mais achatada na cauda inferior - particularmente em torno do mínimo - e aumentar um pouco a concentração em torno da moda, mas seus efeitos diminuem à medida que caminhamos para o topo da distribuição. ${ }^{9}$

\subsubsection{Sindicatos}

Mais uma vez, não apresentamos as tabelas e figuras aqui a fim de economizar espaço, mas o leitor mais interessado poderá encontrá-los na versão anterior deste artigo (Rodrigues and Menezes-Filho, 2003) ou pedi-los junto aos autores.

Quando acrescentamos para o período de 1988-1999 os sindicatos e o atributo cor entre as características individuais, colocamos o grau de filiação sindical após os efeitos do salário mínimo, mas antes dos impactos da educação e dos demais atributos, na primeira ordem de decomposição. Na ordem inversa, ao contrário, os sindicatos aparecem após os atributos individuais e após o fator educação, mas antes do salário mínimo.

Na primeira ordem de decomposição, a inclusão da filiação sindical reduz a importância da educação para valores entre 30\% e 40\% dos índices de Gini e de Theil (para homens e mulheres), o que sugere que

\footnotetext{
${ }^{8}$ As figuras da ordem inversa estão disponíveis com os autores.

${ }^{9}$ As mudanças qualitativas nas figuras associados aos demais fatores explicativos foram as mesmas que as encontradas para o período 1981-1988. Não as expusemos a fim de economizar espaço, mas também estão disponíveis com os autores.
} 
Figure 1: Densidade do log do salário real em 1988 ajustada pelos fatores indicados

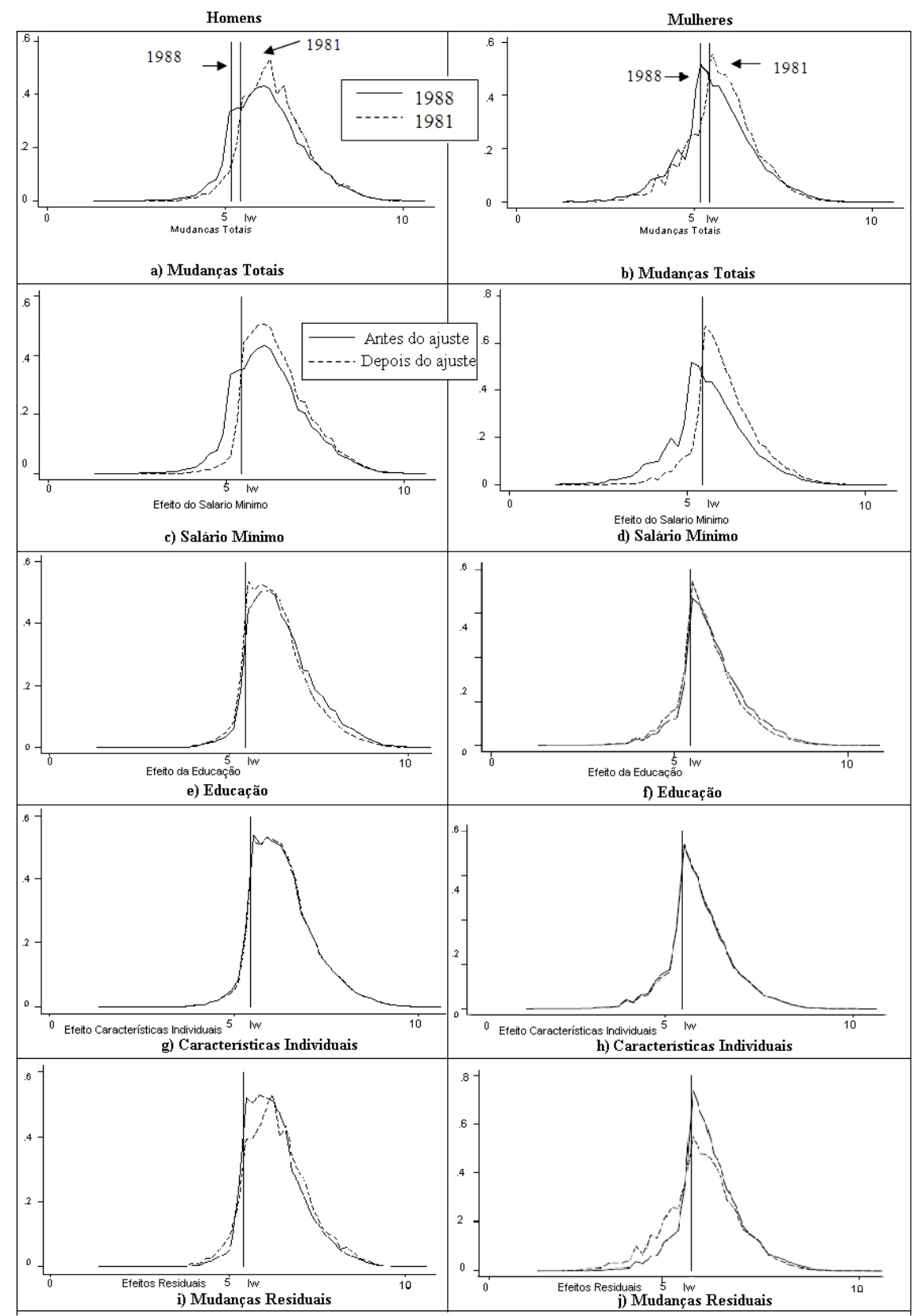


Table 3: Decomposições no período: 1988-1999

\begin{tabular}{|c|c|c|c|c|c|}
\hline \multicolumn{6}{|c|}{ Decompondo as mudanças dos índices de dispersão salarial:1988-1999 } \\
\hline \multirow[b]{2}{*}{ Estatística } & \multirow[b]{2}{*}{$\begin{array}{c}\text { Mudança } \\
\text { total } \\
1999-1988\end{array}$} & \multicolumn{4}{|c|}{ Efeitos de: } \\
\hline & & Salário mínimo & Educação & $\begin{array}{c}\text { Características } \\
\text { individuais }\end{array}$ & $\begin{array}{c}\text { Mudanças não } \\
\text { explicadas }\end{array}$ \\
\hline \multicolumn{6}{|l|}{ Homens } \\
\hline \multirow[t]{2}{*}{ Desvio-Padrão } & $-0,086$ & 0,031 & 0,081 & 0,012 & $-0,210$ \\
\hline & & $35,75 \%$ & $-95,01 \%$ & $-14,58 \%$ & $245,33 \%$ \\
\hline \multirow[t]{2}{*}{$90-10$} & $-0,548$ & 1,667 & 1,667 & 0,000 & $-3,882$ \\
\hline & & $-303,87 \%$ & $-303,87 \%$ & $0,00 \%$ & $707,74 \%$ \\
\hline \multirow[t]{2}{*}{ Gini } & 0,039 & 0,009 & 0,050 & 0,005 & $-0,103$ \\
\hline & & $-23,76 \%$ & $-125,91 \%$ & $-12,44 \%$ & $-262,18 \%$ \\
\hline \multirow[t]{2}{*}{ Theil } & $-0,087$ & 0,0180 & 0,080 & 0,008 & $-0,193$ \\
\hline & & $-20,24 \%$ & $-91,61 \%$ & $-8,99 \%$ & $220,76 \%$ \\
\hline \multicolumn{6}{|l|}{ Mulheres } \\
\hline \multirow[t]{2}{*}{ Desvio-Padrão } & $-0,128$ & $-0,007$ & 0,065 & 0,020 & $-0,206$ \\
\hline & & $5,23 \%$ & $-50,52 \%$ & $-15,32 \%$ & $160,66 \%$ \\
\hline \multirow[t]{2}{*}{$90-10$} & $-5,417$ & $-0,127$ & 0,385 & 0,673 & $-6,347$ \\
\hline & & $2,35 \%$ & $-7,10 \%$ & $-12,42 \%$ & $117,17 \%$ \\
\hline \multirow[t]{2}{*}{ Gini } & $-0,034$ & 0,006 & 0,045 & 0,007 & $-0,092$ \\
\hline & & $-17,53 \%$ & $-129,77 \%$ & $-21,16 \%$ & $268,31 \%$ \\
\hline \multirow[t]{2}{*}{ Theil } & $-0,063$ & 0,014 & 0,082 & 0,014 & $-0,172$ \\
\hline & & $-21,75 \%$ & $-131,10 \%$ & $-21,50 \%$ & $274,20 \%$ \\
\hline \multicolumn{6}{|c|}{ Revertendo a ordem de decomposição: 1988-1999 } \\
\hline & $\begin{array}{c}\text { Mudança } \\
\text { total }\end{array}$ & $\begin{array}{c}\text { Características } \\
\text { individuais }\end{array}$ & Educação & $\begin{array}{c}\text { Salário } \\
\text { mínimo }\end{array}$ & $\begin{array}{c}\text { Mudanças não } \\
\text { explicadas }\end{array}$ \\
\hline \multicolumn{6}{|l|}{ Homens } \\
\hline \multirow[t]{2}{*}{ Desvio-padrão } & $-0,086$ & 0,029 & 0,044 & 0,052 & $-0,21$ \\
\hline & & $-33,39 \%$ & $-51,17 \%$ & $-60,79 \%$ & $245,33 \%$ \\
\hline \multirow[t]{2}{*}{$90-10$} & $-0,548$ & 0,544 & 1,544 & 1,245 & $-3,882$ \\
\hline & & $-99,26 \%$ & $-281,54 \%$ & $-226,94 \%$ & $707,74 \%$ \\
\hline \multirow[t]{2}{*}{ Gini } & $-0,039$ & 0,001 & 0,024 & 0,038 & $-0,103$ \\
\hline & & $-2,94 \%$ & $-61,60 \%$ & $-97,56 \%$ & $262,18 \%$ \\
\hline \multirow[t]{2}{*}{ Theil } & $-0,087$ & $-0,006$ & 0,041 & 0,07 & $-0,193$ \\
\hline & & $7,22 \%$ & $-47,25 \%$ & $-80,84 \%$ & $220,76 \%$ \\
\hline \multicolumn{6}{|l|}{ Mulheres } \\
\hline \multirow[t]{2}{*}{ Desvio-padrão } & $-0,128$ & 0,057 & 0,029 & $-0,008$ & $-0,206$ \\
\hline & & $-44,40 \%$ & $-22,56 \%$ & $6,32 \%$ & $160,66 \%$ \\
\hline \multirow[t]{2}{*}{$90-10$} & $-5,417$ & 1,326 & 0,662 & $-1,058$ & $-6,347$ \\
\hline & & $-24,48 \%$ & $-12,22 \%$ & $19,52 \%$ & $117,17 \%$ \\
\hline \multirow[t]{2}{*}{ Gini } & $-0,034$ & 0,026 & 0,017 & 0,015 & $-0,092$ \\
\hline & & $-75,20 \%$ & $-49,51 \%$ & $-43,72 \%$ & $268,31 \%$ \\
\hline \multirow[t]{2}{*}{ Theil } & $-0,063$ & 0,058 & 0,023 & 0,029 & $-0,172$ \\
\hline & & $-92,02 \%$ & $-36,78 \%$ & $-45,54 \%$ & $-274,20 \%$ \\
\hline
\end{tabular}

: Fonte: Tabela construída pelos autores com base nos dados das PNDAs. 
Figure 2: Densidade do log do salário real em 1999 ajustada pelos fatores indicados

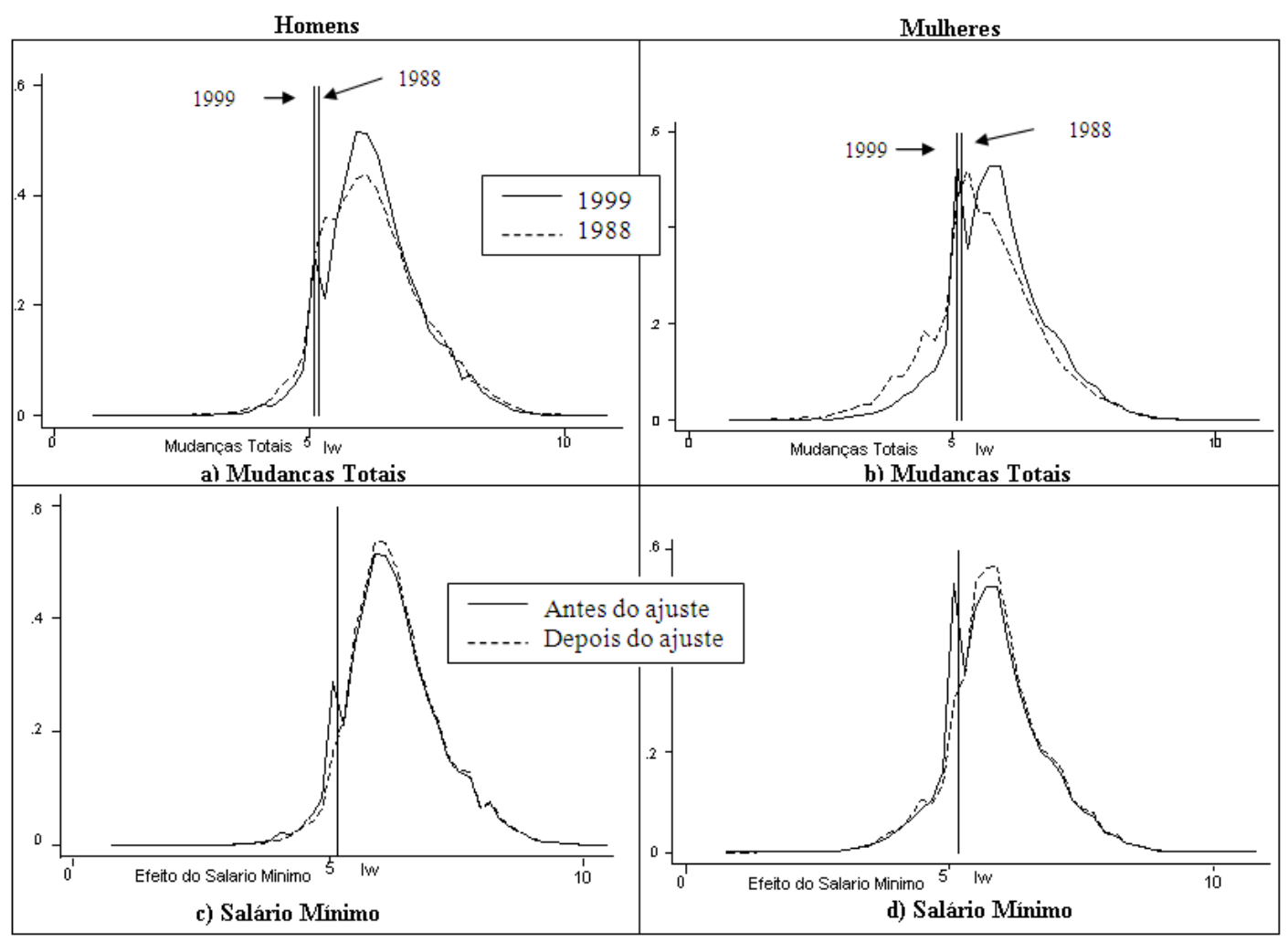

a relação entre sindicalização e educação tenha alguma importância na distribuição salarial. Os efeitos dos atributos individuais e das mudanças não explicadas, por sua vez, não mudam muito. Além disso, para nenhum deles muda o sentido dos efeitos.

$O$ efeito do aumento da sindicalização ao longo desse período parece ter sido o de aumentar a desigualdade salarial. Para todos os índices utilizados, o contrafactual associado a um menor grau de sindicalização indicou queda na desigualdade. Entre os homens esse fator, explicou $85 \%$ do Gini e $59 \%$ do Theil. Entre as mulheres, $99 \%$ do Gini e $105 \%$ do Theil.

Quando revertemos a decomposição, no entanto, a magnitude dos efeitos da sindicalização caiu abruptamente: embora apresentassem os mesmos sinais da decomposição anterior, foram próximos de zero para homens e mulheres em todas as medidas utilizadas. Esses resultados sugerem que os efeitos da relação entre filiação sindical, grau de escolaridade e outros atributos individuais são bastante grandes sobre a densidade salarial, mas o efeito dos sindicatos isoladamente é muito pequeno. De qualquer forma, um maior grau de sindicalização parece aumentar a desigualdade, ainda que muito pouco. Tal resultado não é surpresa se levarmos em conta que a dispersão salarial dos trabalhadores sindicalizados é maior que a dispersão salarial dos não sindicalizados. Portanto, quando diminuímos o grau de filiação sindical na densidade contrafactual dos salários, sem alterar o prêmio pela sindicalização, a desigualdade diminuiu. Além disso, os trabalhadores sindicalizados têm maior nível educacional que os não sindicalizados, daí um efeito maior desse fator quando relacionado aos anos de estudos. Arbache (2002) encontra resultados parecidos com os nossos e sugere que o desenho institucional dos 
sindicatos no Brasil deva incentivar uma maior filiação dos trabalhadores mais qualificados, bem como induzir os sindicatos a atuarem com vistas ao eleitor mediano e a defender políticas favoráveis aos trabalhadores mais qualificados.

\subsection{Setor formal e setor informal}

\subsubsection{Estatísticas}

Com a finalidade de verificar se o mínimo teria efeitos diferenciados entre os setores formais e informais, aplicamos também essa metodologia separadamente para quatro grupos de acordo com o sexo e com a carteira de trabalho. Para tal, precisamos assumir a hipótese de segmentação total entre esses setores. No período de 1981-1988, a desigualdade aumentou para todos os grupos, mas a dispersão entre os informais foi sempre maior que entre os trabalhadores formais. Além disso, como veremos adiante, a densidade entre os sem carteira assinada estava altamente concentrada em torno do mínimo - o que sugere que o mínimo terá um efeito muito grande para este grupo. De fato, quando aplicamos a decomposição, entre os homens com carteira assinada o mínimo explica $47 \%$ do Gini e $41 \%$ do Theil, enquanto que entre os homens do setor informal, o mínimo explica $61 \%$ do Gini e $73 \%$ do Theil. Entre as mulheres com carteira, o mínimo explica $45 \%$ do Gini e $44 \%$ do Theil, já para as sem carteira, $147 \%$ do Gini e $123 \%$ do Theil (Tabela 4). O efeito do mínimo, portanto, é claramente maior entre os trabalhadores do setor informal que entre os do setor formal da economia. Este resultado, como destacam Amadeo et al. (2000), pode resultar em parte da possibilidade que os empregados têm de levar seus empregadores à justiça, a fim de receber por seus direitos como trabalhador, mesmo que seus contratos não tenham sido ratificados pelo Ministério do Trabalho.

Os efeitos da educação e dos demais atributos individuais são qualitativamente os mesmos dos exercícios anteriores, com destaque para o fato de que a escolaridade parece ser mais importante para o setor formal que para o setor informal.

Para o período de 1988-1999, porém, os resultados são pouco robustos. Na primeira ordem da decomposição, os efeitos do mínimo são pequenos e apresentam sinal contrário ao esperado, embora seus efeitos ainda sejam maiores para o setor informal. Na ordem inversa, porém, os efeitos apresentam o sinal esperado e parecem ser mais importantes para o setor formal do que para o setor informal (além de serem maiores em módulo que na decomposição anterior). As tabelas com estes resultados estão disponíveis em Rodrigues and Menezes-Filho (2003, 2004). Não pudemos constatar, portanto, robustez nas estimações. De fato, na literatura brasileira não há consenso sobre os efeitos diferenciados do mínimo nos dois setores. Por um lado, há tanto evidências favoráveis ao "efeito farol" em ambos os setores (Fajnzylber, 2001), como evidências desfavoráveis ao efeito do mínimo no setor informal (Cacciamali et al., 1994). Além disso, Neri (1997) encontra resultados diferentes dos nossos, pois ele observa uma maior efetividade da política do mínimo no setor formal ao longo dos anos 80 , mas percebe o resultado inverso para os anos 90, isto é, maiores efeitos do mínimo entre os trabalhadores informais.

\subsubsection{Figuras}

Nas figuras (Figuras 3 e 4), referentes ao período 1981-1988, notamos em primeiro lugar, como já havíamos destacado, que a concentração em torno do salário mínimo é muito grande entre os trabalhadores sem carteira assinada; enquanto que para os trabalhadores formais há um pico no valor real do mínimo - como aparecia nas figuras anteriores. Para todos os grupos, o aumento do mínimo empurraria a distribuição para a direita e diminuiria sua dispersão. ${ }^{10}$

\footnotetext{
${ }^{10}$ As figuras referentes aos setores formais e informais para o período de 1988-1999 também estão disponíveis em Rodrigues and Menezes-Filho $(2003,2004)$ ou junto aos autores.
} 
Table 4: Decomposições no período: 1981-1988

\begin{tabular}{|c|c|c|c|c|c|}
\hline \multicolumn{6}{|c|}{ Decompondo as mudanças dos índices de dispersão salarial dos trabalhadores } \\
\hline \multicolumn{6}{|c|}{ COM Carteira de Trabalho assinada: $1981-1988$} \\
\hline \multirow[b]{2}{*}{ Estatística } & \multirow[b]{2}{*}{$\begin{array}{c}\text { Mudança total } \\
1988-1981 \\
\end{array}$} & \multicolumn{4}{|c|}{ Efeitos de: } \\
\hline & & Salário & Educação & $\begin{array}{c}\text { Características } \\
\text { individuais }\end{array}$ & $\begin{array}{c}\text { Mudanças não } \\
\text { explicadas }\end{array}$ \\
\hline \multicolumn{6}{|l|}{ Homens } \\
\hline \multirow[t]{2}{*}{ Desvio-Padrão } & 0,088 & 0,058 & 0,041 & 0,001 & $-0,012$ \\
\hline & & $65,79 \%$ & $47,05 \%$ & $0,98 \%$ & $-13,83 \%$ \\
\hline \multirow[t]{2}{*}{$90-10$} & 2,234 & 1,577 & 0,750 & $-0,036$ & $-0,057$ \\
\hline & & $70,58 \%$ & $33,57 \%$ & $-1,60 \%$ & $-2,56 \%$ \\
\hline \multirow[t]{2}{*}{ Gini } & 0,046 & 0,022 & 0,021 & 0,000 & $-0,003$ \\
\hline & & $47,50 \%$ & $45,33 \%$ & $0,11 \%$ & $7,08 \%$ \\
\hline \multirow[t]{2}{*}{ Theil } & 0,1 & 0,041 & 0,033 & $-0,001$ & 0,027 \\
\hline & & $41,24 \%$ & $32,67 \%$ & $-0,88 \%$ & $26,96 \%$ \\
\hline \multicolumn{6}{|l|}{ Mulheres } \\
\hline \multirow[t]{2}{*}{ Desvio-Padrão } & 0,088 & 0,050 & 0,027 & 0,004 & 0,006 \\
\hline & & $57,15 \%$ & $31,15 \%$ & $4,53 \%$ & $7,19 \%$ \\
\hline \multirow[t]{2}{*}{$90-10$} & 1,101 & 0,460 & 0,799 & 0,005 & $-0,162$ \\
\hline & & $41,73 \%$ & $72,52 \%$ & $0,45 \%$ & $-14,71 \%$ \\
\hline \multirow[t]{2}{*}{ Gini } & 0,061 & 0,028 & 0,014 & 0,002 & 0,017 \\
\hline & & $45,38 \%$ & $22,87 \%$ & $3,77 \%$ & $27,98 \%$ \\
\hline \multirow[t]{2}{*}{ Theil } & 0,119 & 0,053 & 0,016 & 0,005 & 0,045 \\
\hline & & $44,27 \%$ & $13,78 \%$ & $4,22 \%$ & $37,74 \%$ \\
\hline \multicolumn{6}{|c|}{ Decompondo as mudanças dos índices de dispersão salarial dos trabalhadores } \\
\hline \multicolumn{6}{|c|}{ SEM Carteira de Trabalho assinada: 1981-1988 } \\
\hline Estatística & $\begin{array}{c}\text { Mudança total } \\
1988-1981\end{array}$ & Salário & Educação & $\begin{array}{c}\text { Características } \\
\text { individuais }\end{array}$ & $\begin{array}{c}\text { Mudanças não } \\
\text { explicadas }\end{array}$ \\
\hline \multicolumn{6}{|l|}{ Homens } \\
\hline \multirow[t]{2}{*}{ Desvio-padrão } & 0,105 & 0,060 & 0,048 & $-0,004$ & 0,002 \\
\hline & & $56,86 \%$ & $45,51 \%$ & $-3,81 \%$ & $1,43 \%$ \\
\hline \multirow[t]{2}{*}{$90-10$} & 2,683 & 1,701 & $-0,141$ & 0,521 & 0,602 \\
\hline & & $63,38 \%$ & $-5,24 \%$ & $19,42 \%$ & $22,45 \%$ \\
\hline \multirow[t]{2}{*}{ Gini } & 0,051 & 0,031 & 0,021 & 0,000 & $-0,002$ \\
\hline & & $61,59 \%$ & $40,79 \%$ & $0,57 \%$ & $-2,96 \%$ \\
\hline \multirow[t]{2}{*}{ Theil } & 0,118 & 0,087 & 0,031 & 0,003 & $-0,003$ \\
\hline & & $73,64 \%$ & $26,43 \%$ & $2,57 \%$ & $-2,64 \%$ \\
\hline \multicolumn{6}{|l|}{ Mulheres } \\
\hline \multirow[t]{2}{*}{ Desvio-padrão } & 0,073 & 0,092 & 0,019 & 0,006 & $-0,043$ \\
\hline & & $125,15 \%$ & $26,23 \%$ & $7,72 \%$ & $-59,03 \%$ \\
\hline \multirow[t]{2}{*}{$90-10$} & 4,167 & 4,813 & $-0,747$ & 0,383 & $-0,282$ \\
\hline & & $115,52 \%$ & $-17,93 \%$ & $9,19 \%$ & $-6,77 \%$ \\
\hline Gini & $-0,034$ & 0,051 & 0,003 & 0,000 & $-0,019$ \\
\hline & & $147,51 \%$ & $8,87 \%$ & $-0,29 \%$ & $-56,12 \%$ \\
\hline Theil & 0,096 & 0,117 & $-0,002$ & $-0,004$ & $-0,016$ \\
\hline & & $122,95 \%$ & $-2,09 \%$ & $-4,19 \%$ & $-16,65 \%$ \\
\hline
\end{tabular}

: Fonte: Tabela construída pelos autores com base nos dados das PNDAs. 
Figure 3: Densidade do log do salário real em 1988 ajustada pelos fatores indicados

\section{HOMENS}

Setor Formal

Setor Informal

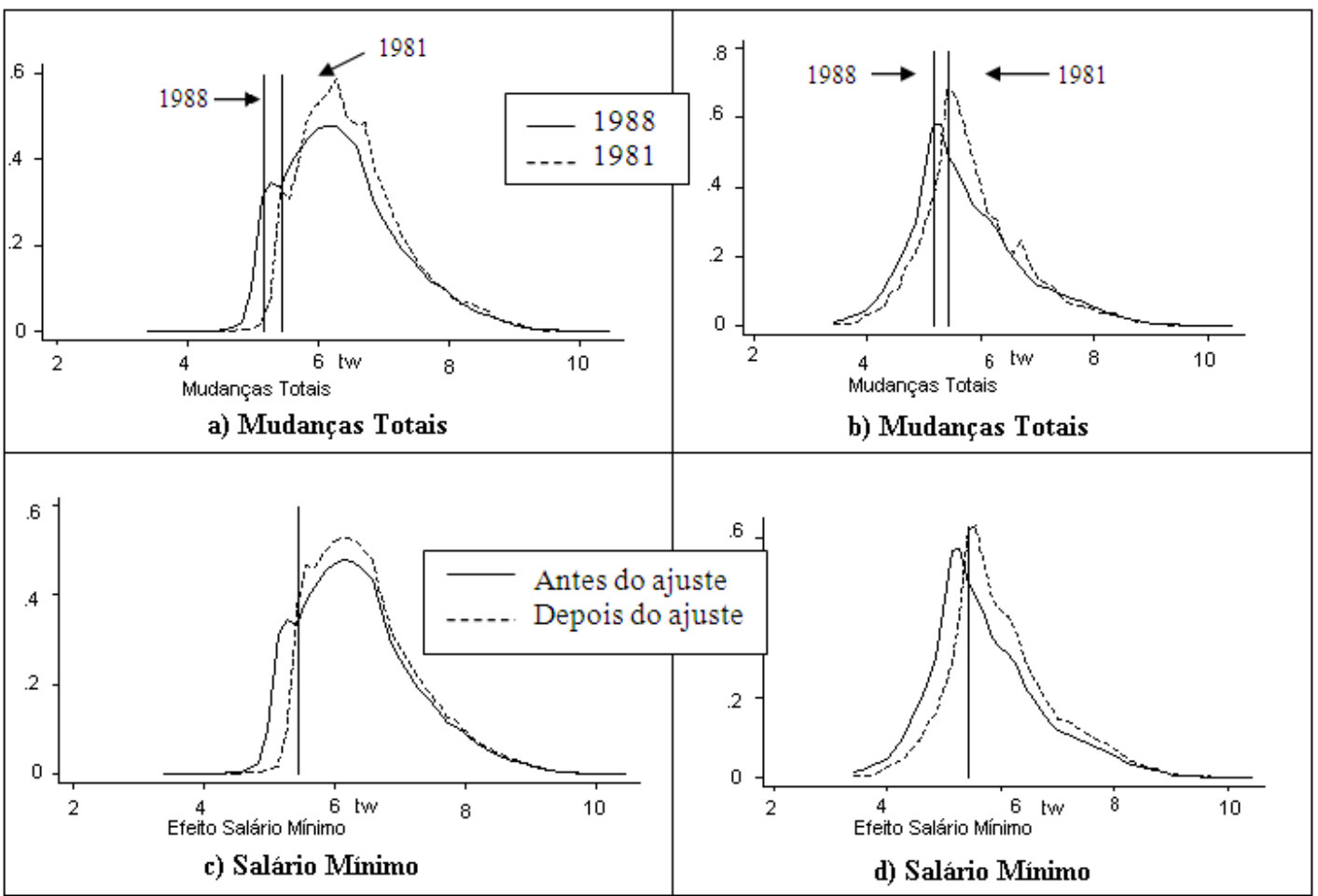

\section{CONSIDERAÇÕES FINAIS}

Este trabalho teve como objetivo avaliar o papel do salário mínimo na distribuição salarial do Brasil entre 1981 e 1999. Para tal, utilizamos os dados das PNADs para os anos de 1981, 1988 e 1999, para as regiões Sul, Sudeste e Distrito Federal, e empregamos um método semiparamétrico desenvolvido por DiNardo et al. (1996) que ainda não havia sido empregado no Brasil. Apesar das limitações dessa abordagem no tocante aos possíveis efeitos advindos de um arcabouço de equilíbrio geral, ela permite uma inspeção visual clara sobre quais os pontos da distribuição salarial cada fator explicativo exerce maior influência e uma comparação do peso relativo de cada um deles.

Verificamos que a queda do salário mínimo real ao longo desse período deve ter servido para aumentar a dispersão salarial. Entre 1981 e 1988, particularmente, ela explica uma proporção substancial do aumento da desigualdade salarial - principalmente para as mulheres. Vimos que um aumento real do salário mínimo empurraria a distribuição para a direita e diminuiria sua dispersão. Também teria efeitos cada vez menores à medida em que caminhamos para o topo da distribuição - o que está de acordo com os resultados mais recentes obtidos pela literatura brasileira, além de consistente com o chamado "efeito farol". É interessante destacar que as variações das medidas de desigualdade apontam para um peso relativo do salário mínimo bastante elevado, mesmo quando consideramos a decomposição na ordem inversa, isto é, "limpo" dos demais fatores. 
Figure 4: Densidade do log do salário real em 1988 ajustada pelos fatores indicados

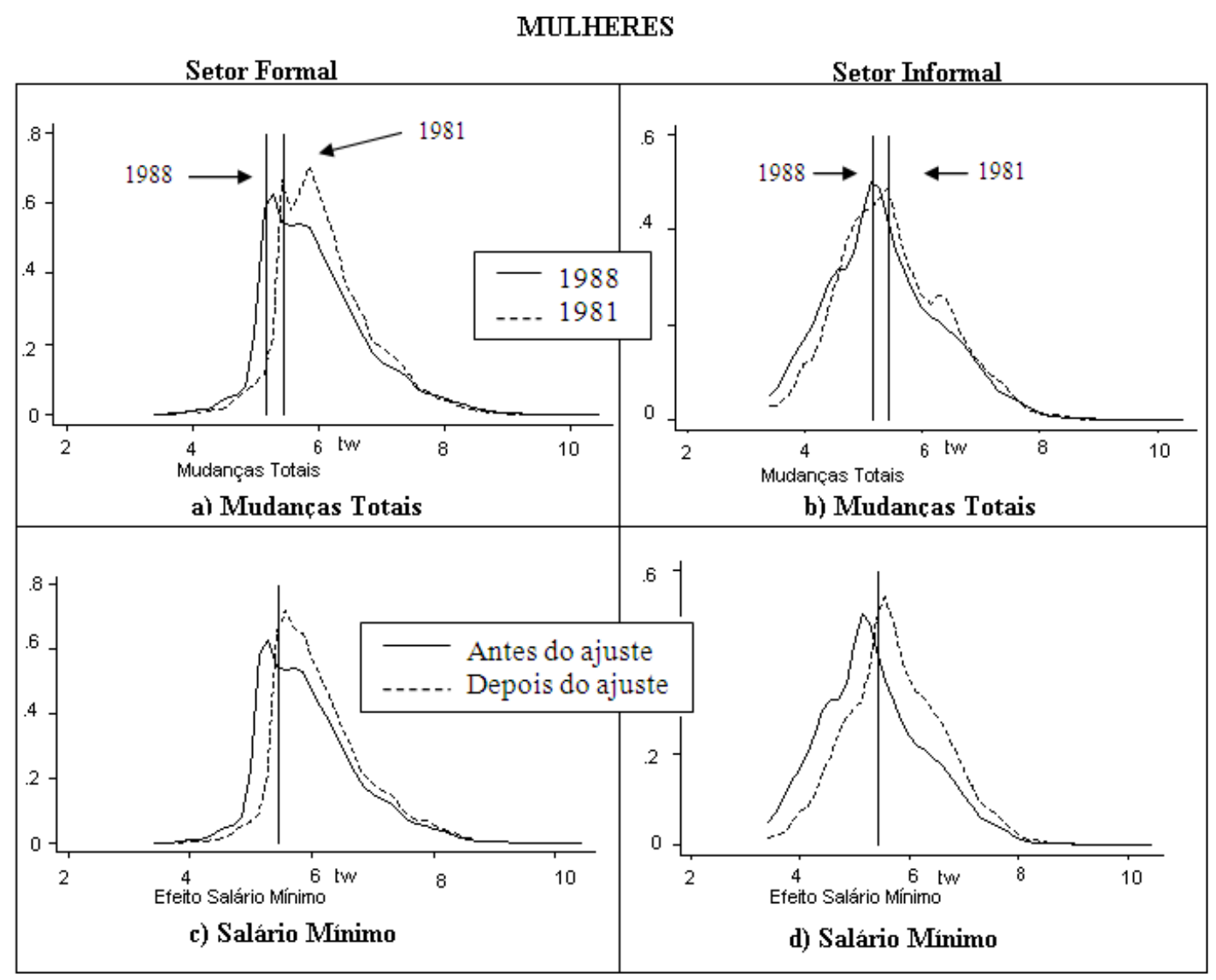

Já os efeitos sobre os setores formais e informais - assumindo segmentação total entre eles - pareceram maiores para o setor informal no período 1981-1988. Entretanto, para o período 1988-1999, os resultados foram pouco robustos. Esta falta de robustez com relação aos efeitos do mínimo no setor informal parece ser uma constante na literatura brasileira.

Este trabalho sugere que a evolução do salário mínimo, da composição da educação, do grau de sindicalização e das demais características individuais devem ter servido para aumentar a desigualdade salarial ao longo das duas últimas décadas. A relativa estabilidade na nossa desigualdade neste período deve seguir, portanto, das mudanças não explicadas por esta abordagem. Esses resultados sugerem, consequentemente, a importância de se investigar a composição desses demais fatores para melhor compreender a evolução da desigualdade no Brasil entre 1981 e 1999. De qualquer forma, o salário mínimo parece ter tido um papel neste período que não deve ser negligenciado.

\section{BIBLIOGRAPHY}

Amadeo, E. J., Gill, I. S., \& Neri, M. (2000). Brazil: The pressure points in labor legislation. Mimeo. 
Arbache, J. S. (2002). Unions and the labour market in Brazil. In Latin American Meeting of the Econometric Society, FGV-EAESP, São Paulo. Econometric Society.

Brown, C. (1999). Minimum wage, employment and the distribution of income. In Ashenfelter, O. \& Card, D., editors, Handbook of Labor Economics, chapter 32. Elsevier.

Cacciamali, M. C., Portela, A., \& Freitas, E. (1994). O papel do salário mínimo nos anos 80: Novas observações para o caso brasileiro. Revista Brasileira de Economia, 48(1).

Corseuil, C. H. \& Foguel, M. N. (2002). Uma sugestão de deflatores para rendas obtidas a partir de algumas pesquisas domiciliares do IBGE. IPEA, mimeo.

DiNardo, J., Fortín, N., \& Lemieux, T. (1996). Labor market institutions and the distribution of wages: 1973-1992: A semi-parametric approach. Econometrica, 64:1001-1044.

Fajnzylber, P. (2001). Minimum wage effects throughout the wage distribution: Evidence from Brazil's formal and informal sectors. Texto para Discussão, CEDEPLAR.

Lemos, S. (2002a). The effects of minimum wages on wages and employment in Brazil - A menu of minimum wage variables. Mimeo, UCL.

Lemos, S. (2002b). The effects of the minimum wages on employment in Brazil. UK: University College London Working Paper.

Macedo, R. B. \& Garcia, M. E. (1978). Observações sobre a política brasileira de salário mínimo. IPE-USP, Texto para Discussão 27.

Menezes-Filho, N. A., Fernandes, R., \& Picchetti, P. (2000). Rising human capital but constant inequality: The education composition effect in Brazil. Universidade de São Paulo, mimeo.

Neri, M. (1997). O reajuste do salário mínimo de maio de 1995. IPEA, Seminários sobre Estudos do Trabalho 10.

Rodrigues, E. A. S. \& Menezes-Filho, N. A. (2003). Salário mínimo e desigualdade no Brasil, 1981-1999: Uma abordagem semiparamétrica. Mimeo.

Rodrigues, E. A. S. \& Menezes-Filho, N. A. (2004). Minimum wage and inequality in Brazil and Mexico, 1981-2000: A semiparametric approach. In XIX LACEA Meeting, San Jose, Costa Rica. LACEA.

Silverman, B. (1986). Density Estimation for Statistics and Data Analysis. Chapman \& Hall, London.

Soares, S. S. D. (2001). O impacto do salário mínimo: A distribuição individual dos rendimentos do trabalho. Texto para Discussão IPEA, Rio de Janeiro.

Velloso, R. (1990). Salário mínimo e a taxa de salários: O caso brasileiro. Pesquisa e Planejamento Econômico, 20(3).

\section{A. DEMONSTRAÇÃO}

O reponderador $\phi_{z}$ é definido como

$$
\phi_{z}(z) \equiv \frac{d F\left(z / t_{z}=81\right)}{d F\left(z / t_{z}=88\right)}
$$


o que implica

$$
\phi_{z}(z) \equiv \frac{f\left(z / t_{z}=81\right)}{f\left(z / t_{z}=88\right)}
$$

Mas como

$$
f\left(z / t_{z}=81\right)=\frac{f\left(z, t_{z}=81\right)}{\operatorname{Pr}\left(t_{z}=81\right)}
$$

E como

$$
f\left(z, t_{z}=81\right)=\operatorname{Pr}\left(t_{z}=81 / z\right) \cdot f(z)
$$

Então,

$$
f\left(z / t_{z}=81\right)=\frac{\operatorname{Pr}\left(t_{z}=81 / z\right) \cdot f(z)}{\operatorname{Pr}\left(t_{z}=81\right)}
$$

E o mesmo vale para $t_{z}=88$. Logo,

$$
\phi_{z}(z)=\frac{\operatorname{Pr}\left(t_{z}=81 / z\right) \cdot f(z)}{\operatorname{Pr}\left(t_{z}=88 / z\right) \cdot f(z)} \cdot \frac{\operatorname{Pr}\left(t_{z}=88\right)}{\operatorname{Pr}\left(t_{z}=81\right)}
$$

Que é o reponderador associado às características individuais. 